\section{Molekulargenetische Diagnostik bei der familiären adenomatösen Polypose (FAP)}

Z. Dobbie
Homöostase des kolonischen Epithels ermöglicht, bedingt durch eine APC-Mutation nicht mehr kontrollieren lässt, führt dies zu einer ungehinderten Zellproliferation in Form eines Polypen.

\section{DNA-Diagnostik}

Die kodierende Sequenz des APC-Gens erstreckt sich über 8000 Basenpaare und ergibt fast keine «hotspots" für Mutationen. So wurden bis heute bereits mehrere hundert verschiedene Mutationen im APCGen identifiziert, was die genetische Untersuchung dieses Genes enorm erschwert. Allerdings konnte man beobachten, dass die Mehrheit aller gefundenen Mutationen doch ein typisches Merkmal aufweist. Da sie sogenannte "nonsense»- oder "frameshift»-Mutationen darstellen, verursachen sie eine Verkürzung des resultierenden APC-Proteins. Deshalb wird in einem ersten Schritt der genetischen Analyse des APC-Genes zuerst das APC-Protein mittels des sogenannten "Protein Truncation Tests" (PTT) auf seine Länge hin untersucht.

Als erstes wurde das APC-Gen bei der bekannten Betroffenen, Heidi, analysiert. Sie hat sich als Trägerin der Mutation im Kodon 1309 des APC-Genes erwiesen. Es ist bekannt, dass der Schweregrad der FAP-Erkrankung, zumindest teilweise, mit der Lokalisation der Mutation innerhalb der für verschiedene funktionelle Domänen des Proteins kodierenden Regionen des APC-Genes korrelierbar ist (Abb. 1). Die Mutation 1309 prädisponiert zwar bekannterweise zu einer ausgeprägten und frühmanifestierenden Polypose, ist aber nur selten in Verbindung mit der Entwicklung verschiedener extrakolonischen Manifestationen, wie Desmoide, multiple Osteome und multiple Fibrome, gebracht worden.

Im zweiten Schritt wurde Heidis Sohn Lukas auf die Mutation im Kodon 1309 hin untersucht und tatsächlich als Mutationsträger identifiziert. Eine Planung der engmaschigen (bis zur Entwicklung der ersten Polypen etwa 2 jährlichen) gastroenterologischen Untersuchungen wurde deswegen durchgeführt.

Da die genetische Analyse die Ursache der FAPErkrankung eindeutig als 1309-APC-Mutation identifizieren konnte, wurde es möglich, alle anderen Familienmitglieder, die potentiell Träger dieser $\mathrm{Mu}-$ tation sein könnten, zu untersuchen. Heidis jüngere Schwester Regine konnte so als Nichtträgerin identifiziert werden. Somit kann man bei ihr auf engmaschige endoskopische Untersuchungen verzichten.

\section{Zur Bedeutung der DNA-Diagnostik}

Das aufgrund der molekulargenetischen Abklärung des APC-Gens bestehende Risiko für FAP ist bei Lukas sehr hoch. Da dieses Risiko bereits in jungem Alter des Patienten bekannt ist, können jedoch prophylaktische Untersuchungen und ein rechtzeitiger Eingriff, der eine Tumorentstehung vermeiden lässt,
Dr. phil. II Zuzana Dobbie

Abteilung Medizinische Genetik UKBB

Molekulargenetisches Labor

Dept. Klinisch-Biologische Wissenschaften

CH-4005 Basel \begin{abstract}
Gleichgewicht dieser zwei Prozesse, das eine normale
\end{abstract}




\section{Abbildung 1}

Genotyp/Phänotyp-Korrelationen in FAP.

Die Lokalisation der Mutation im APC-Gen korreliert mit dem Schweregrad der FAP-Erkrankung.

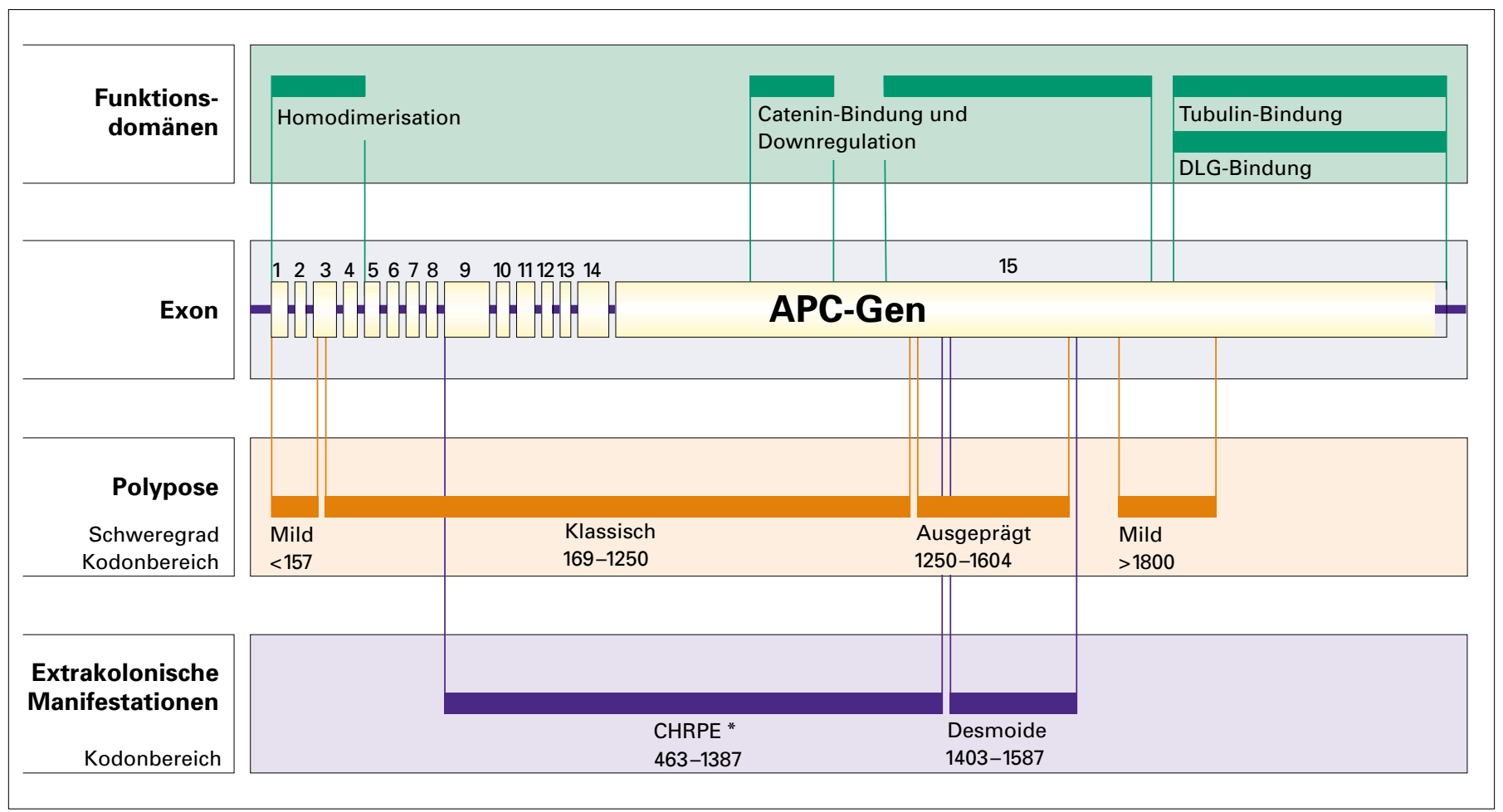

* Congenital hypertrophy of the retinal pigment epithelium

durchgeführt wurden. Bei Heidis Schwester Regine führt das Resultat der genetischen Analyse nicht nur zur enormen psychischen Entlastung, sondern auch zur Befreiung von jeglichen endoskopischen Kontrolluntersuchungen.

\section{Was versteht man unter PTT?}

Das APC-Gen wird mittels PTT in sechs separaten Teilen analysiert (Abb. 2). Jedes Teil, das etwa 1500-1800 Basenpaare enthält, wird hochspezifisch mit der Polymerasen-Kettenreaktion (PCR) amplifiziert und mittels In-vitro-Transkription und Translation in das entsprechende Protein umgeschrieben. So entsteht ein "synthetisch» erzeugtes Protein, das auf seine genaue Länge auf einem Polyacrylamidgel im elektrischen Feld hin untersucht und meist autoradiographisch visualisiert wird. Enthält das amplifizierte Genstück keine Mutation, welche die danach folgende Translation unterbrechen würde, werden anhand der zwei Genallele zwei gleiche Proteine synthetisiert, die auf dem Gel als eine Bande erscheinen. Befindet sich da jedoch eine Stop-Mutation, wird zusätzlich zu dem erwarteten ein kürzeres Proteinprodukt vorkommen, das als weitere Bande auf dem Gel sichtbar ist.

Der PTT dient allerdings lediglich als erster Schritt der genetischen Analyse des APC-Genes. Sollte sich als Resultat des PTT ein Hinweis auf eine Mutation ergeben, muss die genaue Lokalisation und Art dieser Veränderung mittels einer detaillierten DNASequenzierung bestimmt werden. 


\section{Abbildung 2}

Protein Truncation Test (PTT).

\section{Gesund}

(Kontrolle)

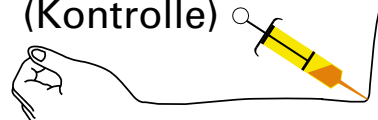

Normales APC-Gen

\section{Patient}

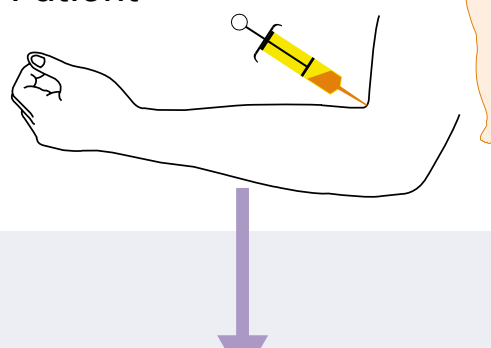

Mutiertes APC-Gen

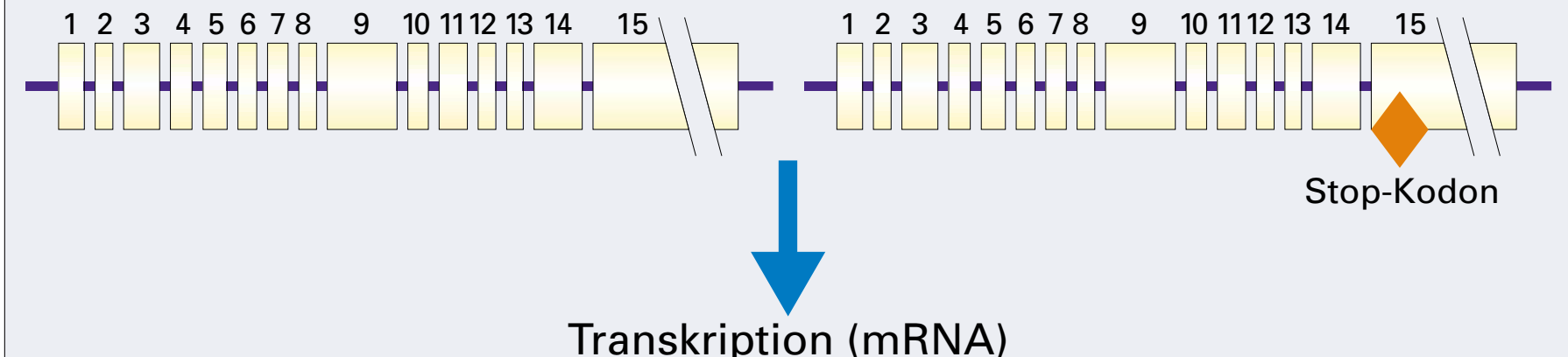

Transkription (mRNA)

Auftrennung (Elektrophorese)

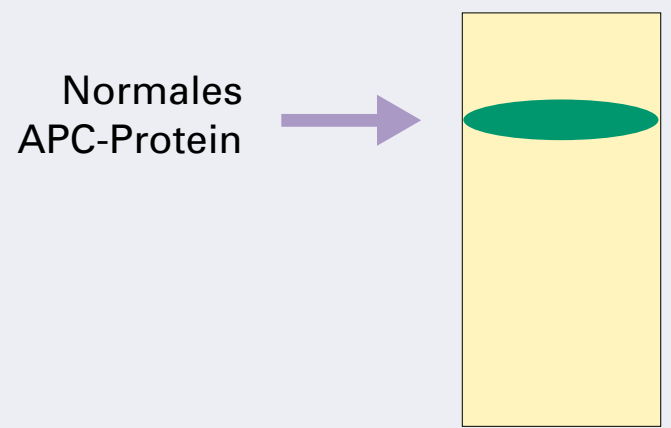

$\mathrm{APC} \oplus / \oplus$

Gesund
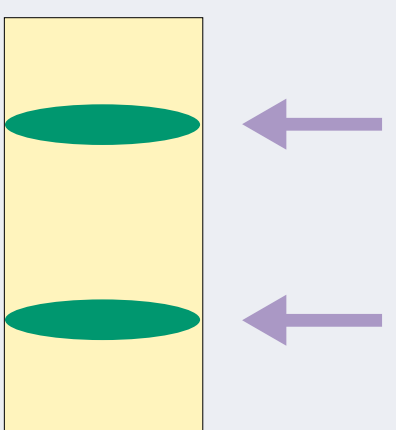

Normales

APC-Protein

Verkürztes

APC-Protein 